\title{
Teor e exportação de macro e micronutrientes nos tubérculos de cultivares de batata em função do nitrogênio
}

\author{
Heder Braun ( $\left.{ }^{*}\right)$; Paulo Cezar Rezende Fontes (1); Camilo Busato (²); Paulo Roberto Cecon (1) \\ (') Departamento de Fitotecnia, Universidade Federal de Viçosa, UFV, 36570-000 Viçosa (MG). E-mail: hederbraun@hotmail.com (*) \\ Autor correspondente; pacerefo@ufv.br; cecon@dpi.ufv.br \\ (2) Instituto de Defesa Agropecuária e Florestal do Espírito Santo, IDAF, 29700-011 Colatina (ES).E-mail: camilobusato@yahoo.com.br
}

Recebido: 22/out./2007; Aceito: 6/ago./2010

\begin{abstract}
Resumo
Objetivou-se avaliar o efeito de doses de nitrogênio $(N)$ sobre os teores e exportações de macro e micronutrientes nos tubérculos de cultivares de batata das mais plantadas no Brasil. Os experimentos foram desenvolvidos na época de outono/ inverno, em solo Podzólico Vermelho-Amarelo Câmbico, de textura argilosa. Foram instalados quatro experimentos, simultaneamente, no campo. Em cada experimento foram avaliadas uma cultivar: Ágata, Asterix, Atlantic e Monalisa e cinco doses de N: 0, 50, 100, 200 e $300 \mathrm{~kg} \mathrm{ha}^{-1}$, na forma de sulfato de amônio, aplicadas no sulco. Cada experimento foi instalado no delineamento de blocos casualizados, com quatro repetições. Nas cultivares de batata Ágata, Asterix, Atlantic e Monalisa não há efeito de doses de N sobre o teor de K, Ca, Mg, S, Fe e Zn. O teor de N e a exportação de N, P e Mn pelos tubérculos, ao contrário, foram influenciadas pelas doses de $\mathrm{N}$ aplicadas em todas as cultivares, embora com padrões diferenciados.
\end{abstract}

Palavras-chave: Solanum tuberosum L., adubação nitrogenada, concentração.

\section{Macro and micronutrient concentration and accumulation in tuber of potato cultivars as affected by nitrogen}

\begin{abstract}
The objective of this paper was to evaluate the effect of nitrogen $(N)$ on concentration and accumulation of macro and micronutrients in tuber of the most widely planted potato cultivars in Brazil. The experiments were carried out during fall/ winter season, in a typic Hapludult soil. Four experiments were simultaneously set in the field. In each experiment one potato cultivar, Ágata, Asterix, Atlantic and Monalisa, and five $\mathrm{N}$ rates (0, 50, 100, 200, and $\left.300 \mathrm{~kg} \mathrm{ha}^{-1}\right)$, as ammonium sulphate were evaluated. Each experiment was set in randomized complete block design with four repetitions. There was no effect of $\mathrm{N}$ rate on $\mathrm{P}, \mathrm{K}, \mathrm{Ca}, \mathrm{Mg}, \mathrm{S}$, Fe and Zn concentration in potato cultivars Ágata, Asterix, Atlantic and Monalisa. However, the total $\mathrm{N}$ concentration and total $\mathrm{N}, \mathrm{P}$ and $\mathrm{Mn}$ accumulation in the tubers response were affected by $\mathrm{N}$ rates in all the cultivars, with different patterns.
\end{abstract}

Key words: Solanum tuberosum L, nitrogen fertilization, contents.

No Brasil, a batata possui grande importância econômica entre as oleráceas. Em 2008, a produção brasileira foi de 3.636.419 t, em área de 144.400 ha, atingindo a produtividade de $25,18 \mathrm{t} \mathrm{ha}^{-1}$ (Agrianual, 2009).

A batata é relevante alimento na dieta dos povos da maioria dos países. O tubérculo de batata contém proteínas, aminoácidos essenciais, carboidratos, fibras e nutrientes (principalmente potássio). White et al. (2009) relataram que uma amostra de $200 \mathrm{~g}$ de tubérculo fresco é suficiente para fornecer aproximadamente $26 \%$ dos valores diários de referência alimentar de $\mathrm{Cu}$; $17 \%$ a $18 \%$ de K, P e Fe; e $5 \%$ a $13 \%$ de Zn, Mg e Mn, o que torna o produto de alta qualidade para a alimentação humana.

A resposta fisiológica da planta está diretamente relacionada à radiação solar e, fundamentalmente, à intensidade luminosa, ambas ligadas aos processos fotossintéticos. O processo fotossintético é o principal, senão o único, processo de fornecimento de carbono para o crescimento e desenvolvimento das plantas. Os fotoassimilados, produzidos pela atividade fotossintética, são direcionados para o crescimento, sendo a partição para os tubérculos um dos fatores determinantes da produtividade da cultura da batata. A produção de 
matéria seca pela planta e a partição para os tubérculos são influenciados por diversos fatores, tais como interceptação luminosa (HARRIs, 1992), alta temperatura, por aumentar a senescência foliar e reduzir a capacidade fotossintética (Timlin et al., 2006), fotoperíodo (Haverkort e VerhaGeN, 2008), cultivar (Zebarth, et al., 2006; Geremew et al., 2007), época de cultivo (Mustonen et al., 2010), manejo da cultura (GEREMEw et al., 2007) e fertilização nitrogenada (Zebarth e Rosen, 2007).

Na batata, há produção de matéria seca na parte aérea e nos tubérculos, que acumulam a maior quantidade, atingindo de $68 \%$ a $84 \%$ da biomassa total produzida pela planta (SHARIFI et al., 2005; NunEs et al., 2006). Nunes et al. (2006) mostraram que a produção de matéria seca dos tubérculos possui relação direta com a área foliar da planta. Zebarth et al. (2008) relataram que o potencial de acúmulo de matéria seca na batata aumenta com a duração da cor verde do dossel e com a maior disponibilidade de $\mathrm{N}$.

Para produzir matéria seca, a planta de batata necessita de adequado suprimento de nutrientes, dentre os quais o N, importante para o seu crescimento e desenvolvimento. É o nutriente de maior impacto sobre a produção e qualidade de tubérculos. Segundo Sharifi et al. (2005), a fertilização nitrogenada diminui a relação entre massas de tubérculo e parte aérea da planta. $\mathrm{O} \mathrm{N}$ influencia a massa de tubérculos produzida por planta e tanto a deficiência quanto o excesso de $\mathrm{N}$ reduz a produçấo de tubérculos (Silva et al., 2009).

A fim de obter elevada produtividade, é necessário adicionar ao solo quantidades adequadas de fertilizantes, principalmente o nitrogenado. Doses relativamente elevadas, da ordem de $190 \mathrm{~kg} \mathrm{ha}^{-1}$ de $\mathrm{N}$ no plantio da seca e $256 \mathrm{~kg} \mathrm{ha}^{-1}$ de $\mathrm{N}$ no plantio das águas, estão relacionadas à máxima produção da cultura, conforme determinaram SiLva et al. (2009).

Em qualquer cultura, há forte associação entre a quantidade de matéria seca e o acúmulo de nutrientes na planta (Nunes et al., 2006). Na batata, há variaçôes na quantidade de nutrientes acumulados pelos tubérculos, influenciadas, principalmente, por fatores ligados à produção e partição de matéria seca para os tubérculos. Normalmente, os nutrientes mais exportados pelos tubérculos são N e K (Reis Júnior e Monnerat, 2001; Nunes et al., 2006; SREK et al., 2010). Existem variaçôes nas quantidades de nutrientes exportadas pelos tubérculos de batata e seu conhecimento auxilia na determinação da eficiência do programa de adubação.

A necessidade nutricional de qualquer cultura é determinada pela quantidade de nutriente exportada durante o ciclo. Esta exportação dependerá, portanto, da produtividade obtida e do teor de nutrientes. No entanto, o fornecimento de $\mathrm{N}$ deve ser o mais próximo possível da quantidade exportada pela cultura, considerando-se a eficiência de utilização, evitando-se perdas por volatilização e lixiviação de $\mathrm{N}-\mathrm{NO}_{3}$ para as águas subterrâneas. Considerando que são escassos os trabalhos de pesquisa que relacionam doses de $\mathrm{N}$ com teor e exportação de macro e micronutrientes em tubérculos de batata, objetivou-se, com o pressente estudo, avaliar o efeito de doses de $\mathrm{N}$ sobre o teor e a exportaçáo de macro e micronutrientes nos tubérculos das cultivares de batata Ágata, Asterix, Atlantic e Monalisa, de uso generalizado no Brasil.

Os experimentos foram realizados em Viçosa (MG), na época de outono/inverno (abril-julho de 2006), em solo classificado como Podzólico Vermelho-Amarelo Câmbico. O solo possui textura argilosa, com 28, 25 e 47 dag $\mathrm{kg}^{-1}$ de areia, silte e argila respectivamente. As características do solo na camada de $0-20 \mathrm{~cm}$ de profundidade, amostrada antes da instalação dos experimentos, continha $4,60 \mathrm{mg} \mathrm{kg}^{-1}$ de $\mathrm{N}-\mathrm{NO}_{3} ; \mathrm{pH}$ em água de 6,28; $2,74 \mathrm{dag}$ $\mathrm{kg}^{-1}$ matéria orgânica; $66 \mathrm{mg} \mathrm{dm}^{-3} \mathrm{de} \mathrm{P} ; 178 \mathrm{mg} \mathrm{dm}^{-3} \mathrm{de}$

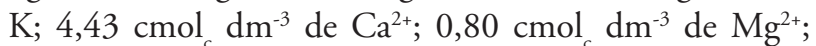
$0,00 \mathrm{cmol}_{c} \mathrm{dm}^{-3} \mathrm{de}$ acidez trocável $\left(\mathrm{Al}^{3+}\right) ; 3,47 \mathrm{cmol}_{\mathrm{c}} \mathrm{dm}^{-3}$ de acidez potencial $\left(\mathrm{H}^{+}+\mathrm{Al}^{3+}\right) ; 5,68 \mathrm{cmol}_{c} \mathrm{dm}^{-3}$ de soma

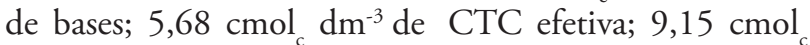
$\mathrm{dm}^{-3}$ de CTC a pH 7,0 e 62,50\% de saturação por base. Durante os experimentos, os valores médios mensais de temperaturas máxima e mínima do ar, umidade relativa e precipitação pluvial foram de $24,9^{\circ} \mathrm{C} ; 12,7^{\circ} \mathrm{C} ; 90,2 \%$ e 20,7 $\mathrm{mm}$ respectivamente.

Foram instalados quatro experimentos, simultaneamente, no campo. Cada um correspondeu a uma cultivar de batata (Solanum tuberosum L.): Ágata, Asterix, Atlantic e Monalisa. Cada experimento, instalado no delineamento em blocos casualizados, com quatro repetiçôes, consistiu de cinco tratamentos ou doses de $\mathrm{N}(0,50,100$, 200 e $300 \mathrm{~kg} \mathrm{ha}^{-1}$ de N), aplicadas no sulco, em pré-plantio, utilizando-se o sulfato de amônio (20\% de N e $24 \%$ de enxofre). As quantidades de fertilizantes aplicados por hectare, no sulco de plantio, foram $1800 \mathrm{~kg}$ de superfosfato simples, $384 \mathrm{~kg}$ de cloreto de potássio, $200 \mathrm{~kg}$ de sulfato de magnésio, $10 \mathrm{~kg}$ de bórax, $10 \mathrm{~kg}$ de sulfato de zinco, $10 \mathrm{~kg}$ de sulfato de cobre e $0,5 \mathrm{~kg}$ de molibdato de sódio.

Cada parcela experimental foi constituída por 28 plantas, em quatro linhas, espaçadas de $0,75 \mathrm{~m}$ entre linhas e 0,25 m entre plantas. As duas linhas laterais e as duas plantas das extremidades das linhas centrais serviram como bordadura. Anteriormente à instalação dos experimentos, a área foi submetida a dois plantios sucessivos de milho, sem utilização de adubo nitrogenado, com o objetivo de reduzir o $\mathrm{N}$ disponível no solo. As plantas de milho foram cortadas mecanicamente e retiradas da área. Após a retirada do milho, foi efetuada a amostragem do solo para determinar a necessidade de calagem e caracterização química e física. Em seguida, realizou-se aração profunda do solo, com arado de aiveca, e duas operaçóes com grade niveladora, para posterior sulcamento. 
O plantio dos tubérculos das quatro cultivares foi realizado em sulcos, em 3 de abril de 2006. Foram utilizadas batatas-semente certificadas, com massa média de 70 $\mathrm{g}$, previamente brotadas, com broto de aproximadamente $3 \mathrm{~cm}$. Não houve tratamento para quebra de dormências dos tubérculos. Aos 22 dias após a emergência (DAE) efetuou-se a amontoa. Durante o período experimental, foram realizadas pulverizaçóes para o controle de pragas e doenças, de acordo com a necessidade. O solo foi mantido com umidade próxima à capacidade de campo, com suspensão da irrigação uma semana antes da colheita. A água utilizada na irrigação possuía $0,48 \mathrm{mg} \mathrm{L}^{-1}$ de $\mathrm{N}^{-\mathrm{NO}_{3}}$ e $0,14 \mathrm{mg} \mathrm{L}^{-1}$ de $\mathrm{N}_{-} \mathrm{NH}_{4}^{+}$. Como no período seco do ano é pouco comum ocorrer volume significativo de chuva, a lâmina aplicada por aspersão situou-se próximo de 386 mm de água (Nunes et al., 2006).

A colheita dos tubérculos ocorreu quando as hastes estavam completamente secas, aos 88, 92, 91 e 84 DAE para as cultivares Ágata, Asterix, Atlantic e Monalisa respectivamente. Amostras de tubérculos classificadas como comerciais foram picadas e submetidas à secagem em estufa com circulação forçada de ar, a $70{ }^{\circ} \mathrm{C}$, até atingirem massa constante. $\mathrm{O}$ teor de matéria seca foi determinado pela relação entre as massas seca $(\mathrm{g})$ e fresca de tubérculos $(\mathrm{g})$.

Após a pesagem, procedeu-se à moagem das amostras em moinho tipo Wiley. Uma subamostra do material moído foi digerida em ácido sulfúrico concentrado. Após a digestáo, a amostra foi analisada quanto ao teor de $\mathrm{N}$ pelo método de Nessler (JaCKson, 1958). Em outra subamostra, o $\mathrm{N}_{-} \mathrm{NO}_{3}$ - foi determinado por espectrofotometria, no comprimento de onda $410 \mathrm{~nm}$ (CATALDO, 1975). $\mathrm{O} \mathrm{N}$ total foi obtido pela soma de $\mathrm{N}$ e $\mathrm{N}-\mathrm{NO}_{3}$.

Outra subamostra da matéria seca de tubérculo foi submetida à digestáo nítrico-perclórica para determinação de fósforo $(\mathrm{P})$, potássio $(\mathrm{K})$, cálcio $(\mathrm{Ca})$, magnésio $(\mathrm{Mg})$, enxofre $(\mathrm{S})$, manganês $(\mathrm{Mn})$, ferro $(\mathrm{Fe})$, cobre $(\mathrm{Cu})$ e zinco $(\mathrm{Zn})$. O K foi dosado em espectrofotômetro de chama; o P em espectrofotômetro, a 725 nm (Braga e
Defelipo, 1974); o $S$ em espectrofotômetro a $420 \mathrm{~nm}$ e $\mathrm{Ca}, \mathrm{Mg}, \mathrm{Cu}, \mathrm{Fe}, \mathrm{Zn}$ e $\mathrm{Mn}$ em espectrofotômetro de absorção atômica (BLANHAR et al., 1965).

Com os valores das concentraçóes de nutrientes nos tubérculos e de produtividade de tubérculos (dados não apresentados), foram calculados os valores da exportação dos nutrientes nos tubérculos.

Cada experimento foi analisado individualmente. Os dados obtidos nos experimentos foram submetidos às análises de variância e de regressão. Os modelos de regressão foram escolhidos com base na significância dos coeficientes de regressão (utilizando-se o teste t e adotando-se o nível de até 5\% de probabilidade), no coeficiente de determinação e de acordo com a ocorrência biológica. Nos modelos obtidos, a dose de $\mathrm{N}$ correspondente à máxima produtividade de tubérculo comercial (DON) foi introduzida para a estimativa da quantidade exportada de macro e micronutrientes em cada cultivar de batata. A DON usada foi, respectivamente, 168,18; 212,22; 175,45; e 193,18 $\mathrm{kg} \mathrm{ha}^{-1}$ de N, para as cultivares Ágata, Asterix, Atlantic e Monalisa (Fontes et al., 2010).

$\mathrm{O}$ coeficiente de variação $(\mathrm{CV} \%)$ referente ao teor e exportação de macro e micronutrientes determinados na matéria seca de tubérculos das cultivares Ágata, Asterix, Atlantic e Monalisa, em função de doses de $\mathrm{N}$ estão especificados na tabela 1 .

A fertilização nitrogenada na cultura da batata favorece o crescimento vegetativo e, consequentemente, a melhor expressão do potencial produtivo da cultura, desde que a quantidade de $\mathrm{N}$ fornecida seja adequada. Ainda, é importante para prevenir que o acúmulo de $\mathrm{N}-\mathrm{NO}_{3}$ nos tubérculos chegue a níveis não aceitáveis no mercado consumidor.

Em estudo realizado por Zebarth et al. (2004), verificou-se aumento quadrático no teor de $\mathrm{N}^{-\mathrm{NO}_{3}}$ nos tubérculos de batata com o aumento das doses de $\mathrm{N}$ em 2000 e 2001, e em 1999 o aumento foi linear, mas segundo os autores, o aumento foi devido ao excesso de umidade no solo nesse ano de cultivo. No presente trabalho, em

Tabela 1. Valores do coeficiente de variação $(\mathrm{CV} \%)$ relacionados à estimativa do teor $\left(\mathrm{dag}_{\mathrm{kg}}{ }^{-1}\right)$ e exportação $\left(\mathrm{kg}\right.$ ha $\left.{ }^{-1}\right)$ de macro $\mathrm{e}$ micronutrientes na matéria seca de tubérculos das cultivares de batata Ágata, Asterix, Atlantic e Monalisa, em experimentos de doses de nitrogênio. Viçosa (MG), 2006

\begin{tabular}{|c|c|c|c|c|c|c|c|c|}
\hline \multirow{3}{*}{ Nutrientes } & \multicolumn{8}{|c|}{ Cultivares } \\
\hline & \multicolumn{2}{|c|}{ Ágata } & \multicolumn{2}{|c|}{ Asterix } & \multicolumn{2}{|c|}{ Atlantic } & \multicolumn{2}{|c|}{ Monalisa } \\
\hline & Teor & Exp. & Teor & Exp. & Teor & Exp. & Teor & Exp. \\
\hline $\mathrm{N}$ total & 9,40 & 7,35 & 6,08 & 7,35 & 6,66 & 7,93 & 8,05 & 9,93 \\
\hline $\mathrm{P}$ & 17,02 & 18,84 & 16,79 & 18,10 & 22,04 & 22,96 & 12,83 & 14,45 \\
\hline K & 10,03 & 12,00 & 10,10 & 10,87 & 12,81 & 16,13 & 9,22 & 8,17 \\
\hline $\mathrm{Ca}$ & 7,27 & 8,11 & 9,07 & 10,11 & 4,41 & 6,69 & 16,22 & 19,03 \\
\hline $\mathrm{Mg}$ & 12,16 & 14,16 & 18,49 & 20,04 & 21,24 & 22,05 & 21,09 & 20,96 \\
\hline$S$ & 15,22 & 13,75 & 18,63 & 19,57 & 18,28 & 19,57 & 12,75 & 13,85 \\
\hline $\mathrm{Cu}$ & 25,67 & 23,09 & 24,72 & 24,91 & 20,45 & 22,31 & 27,08 & 28,71 \\
\hline Mn & 13,67 & 13,82 & 26,42 & 28,78 & 13,39 & 13,75 & 9,98 & 11,85 \\
\hline $\mathrm{Fe}$ & 23,03 & 22,15 & 8,44 & 10,14 & 27,38 & 26,65 & 10,26 & 13,82 \\
\hline $\mathrm{Zn}$ & 15,95 & 17,67 & 22,69 & 23,64 & 10,23 & 11,94 & 8,29 & 12,26 \\
\hline
\end{tabular}


nenhuma cultivar e dose de $\mathrm{N}$ foram detectados qualquer teor de $\mathrm{N}-\mathrm{NO}_{3}$ na matéria seca dos tubérculos, indicando baixa possibilidade de concentrar $\mathrm{N}-\mathrm{NO}_{3}$ em tubérculos de batata. Este resultado é importante para o consumidor, pois quando em alta concentração no organismo humano, o N-NO produzido pela redução do $\mathrm{N}^{-\mathrm{NO}_{3}}$ ao chegar à corrente sanguínea, oxida o ferro da hemoglobina, produzindo a metahemoglobina. Este composto, reagindo com aminas e amidas podem formar nitrosaminas, compostos potencialmente cancerígenos, que levam ao impedimento do transporte do oxigênio dos alvéolos pulmonares para os tecidos, o que pode causar a morte (BoInk e Speijers, 2001).

Em todas as cultivares houve efeito da dose de $\mathrm{N}$ sobre o teor de $\mathrm{N}$ total nos tubérculos (Tabela 2). Os valores do teor de $\mathrm{N}$ total verificados nos tubérculos do presente estudo estáo de acordo com Walworth e Muniz (1993), que encontraram $1,38 \mathrm{dag} \mathrm{kg}^{-1}$ na matéria seca dos tubérculos, no fim do ciclo da batata. Também estão próximos do obtido por SREK et al. (2010), que constataram valor de 1,5 a 2,1 dag kg-1 de N. De acordo com Walworth e Muniz (1993), o teor de N no tubérculo decresce com o avanço do desenvolvimento da batateira, de modo que é relevante a época da sua determinação.

Em nenhuma das cultivares houve efeito da dose de $\mathrm{N}$ sobre o teor dos demais macronutrientes nos tubérculos (Tabela 2). O teor médio de $\mathrm{P}$, em todas as cultivares, foi maior do que os teores de 0,14 e a variação de 0,15 a $0,22 \mathrm{dag} \mathrm{kg}^{-1}$ relatados por WaLworth e Muniz (1993) e SReK et al. (2010), respectivamente. Paula et al. (1986a) também verificaram valores de $\mathrm{P}$ menores do que o constatados no presente estudo.

Com relação ao $\mathrm{K}$, há diversas referências, entre as quais 1,41 a 2,13 dag kg-1 (Walworth e Muniz, 1993) e valores variando de 1,6 a 2,3 dag $\mathrm{kg}^{-1}$ (SREK et al., 2010).
Nos tubérculos de batata geralmente não há altos teores de Ca (Broadley et al., 2006). Paula et al. (1986b) relataram que a quantidade máxima de Ca nos tubérculos aumentou com a adubação, mas reduziu com a idade da planta. O Ca possui baixa mobilidade na planta, pois o sistema radicular absorve o Ca da solução do solo e é transportado pelo xilema até o caule e a folha, partes da planta com taxa de transpiração maior do que a do tubérculo. Esse mecanismo depende da interaçáo genética $x$ ambiente $\mathrm{x}$ práticas culturais, sendo de difícil quantificaçáo. Teores de Ca de 0,09 a $0,12 \mathrm{dag} \mathrm{kg}^{-1}$ foram obtidos por SREK et al. (2010), inferiores, portanto, aos verificados no presente experimento.

Já o teor de $\mathrm{Mg}$ nos tubérculos foi similar ao encontrado por $S_{\text {REK }}$ et al. (2010) que obtiveram valores de 0,07 a $0,11 \mathrm{dag} \mathrm{kg}^{-1}$. Valores de 0,08 a $0,10 \mathrm{dag} \mathrm{kg}^{-1} \mathrm{de} S$ foram encontrados por SREK et al. (2010).

No presente trabalho, apesar das doses crescentes de $S$ aplicadas (provenientes do sulfato de amônio), não houve efeito sobre o teor de $S$ nos tubérculos. Os valores médios foram de 0,154; 0,126; 0,159 e 0,128 dag kg-1 de $S$ para as cultivares Ágata, Asterix, Atlantic e Monalisa respectivamente.

Em todas as cultivares não houve efeito da dose de $\mathrm{N}$ sobre os teores de Fe e $\mathrm{Zn}$ nos tubérculos (Tabela 2). SREK et al. (2010) constataram teores de Fe variando de 29 a $52 \mathrm{mg} \mathrm{kg}^{-1}$, valores inferiores aos obtidos no presente trabalho.

$\mathrm{O}$ efeito da dose de $\mathrm{N}$ sobre os teores de $\mathrm{Cu}$ e de Mn nos tubérculos variou com a cultivar, exceto para Ágata. SReK et al. (2010) relataram teores de Cu nos tubérculos variando de 3,5 a $5,7 \mathrm{mg} \mathrm{kg}^{-1}$. WALWORTH e Muniz (1993) relataram que os teores de $\mathrm{Mn}$ e $\mathrm{Zn}$ nos tubérculos, oscilam de 11,3 a $13,4 \mathrm{mg} \mathrm{kg}^{-1}$ e 17,0 a $18,0 \mathrm{mg} \mathrm{kg}^{-1}$ respectivamente. O teor de $\mathrm{Mn}$ e $\mathrm{Zn}$

Tabela 2. Equaçôes ajustadas para os teores de macro e micronutrientes na matéria seca de tubérculos das cultivares Ágata, Asterix, Atlantic e Monalisa, em função de doses de nitrogênio (N). Viçosa (MG), 2006

\begin{tabular}{|c|c|c|c|c|}
\hline \multirow{2}{*}{ Nutrientes } & \multicolumn{4}{|c|}{ Cultivares } \\
\hline & Ágata & Asterix & Atlantic & Monalisa \\
\hline & \multicolumn{4}{|c|}{ dag kg $^{-1}$} \\
\hline $\mathrm{N}$ total & $\begin{array}{c}\hat{Y}=1,32668+0,00170810^{*} \mathrm{~N}- \\
0,000005836^{*} \mathrm{~N}^{2} \\
\mathrm{R}^{2}=0,99\end{array}$ & $\begin{array}{c}\hat{Y}=1,16701+0,00386530 * \mathrm{~N}- \\
0,00000775776^{*} \mathrm{~N}^{2} \\
\mathrm{R}^{2}=0,89\end{array}$ & $\begin{array}{c}\hat{Y}=1,12025+ \\
0,00152317^{*} \mathrm{~N} \\
r^{2}=0,79\end{array}$ & $\begin{array}{c}\hat{Y}=1,11661+ \\
0,00124252 * \mathrm{~N} \\
\hat{Y}=0,80\end{array}$ \\
\hline$P$ & $\hat{Y}=0,308$ & $\hat{Y}=0,284$ & $\hat{Y}=0,287$ & $\hat{Y}=0,254$ \\
\hline K & $\hat{Y}=2,896$ & $\hat{Y}=2,308$ & $\hat{Y}=2,519$ & $\hat{Y}=2,396$ \\
\hline $\mathrm{Ca}$ & $\hat{Y}=0,723$ & $\hat{Y}=0,591$ & $\hat{Y}=0,725$ & $\hat{Y}=0,631$ \\
\hline $\mathrm{Mg}$ & $\hat{Y}=0,0959$ & $\hat{Y}=0,0644$ & $\hat{Y}=0,0876$ & $\hat{Y}=0,0733$ \\
\hline \multirow[t]{2}{*}{$S$} & $\hat{Y}=0,154$ & $\hat{Y}=0,126$ & $\hat{Y}=0,159$ & $\hat{Y}=0,128$ \\
\hline & \multicolumn{4}{|c|}{$\mathrm{mg} \mathrm{kg}^{-1}$} \\
\hline $\mathrm{Fe}$ & $\hat{Y}=430,548$ & $\hat{Y}=427,280$ & $\hat{Y}=442,301$ & $\hat{Y}=461,068$ \\
\hline $\mathrm{Zn}$ & $\hat{Y}=21,568$ & $\hat{Y}=24,757$ & $\hat{Y}=16,940$ & $\hat{Y}=22,840$ \\
\hline $\mathrm{Cu}$ & $\hat{Y}=2,904$ & $\begin{aligned} \hat{Y}=2,68370 & +0,00631155^{*} \mathrm{~N} \\
r^{2} & =0,93\end{aligned}$ & $\begin{array}{c}\hat{Y}=0,713634+0,00608474^{*} N \\
r^{2}=0,90\end{array}$ & $\hat{Y}=2,454$ \\
\hline $\mathrm{Mn}$ & $\hat{Y}=15,017$ & $\begin{array}{c}\hat{Y}=12,8060+0,0173401^{*} \mathrm{~N} \\
r^{2}=0,81\end{array}$ & $\begin{array}{c}\hat{Y}=21,5029-0,0272185^{*} \mathrm{~N} \\
r^{2}=0,76\end{array}$ & $\begin{array}{c}\hat{Y}=12,731+0,0155153^{*} \mathrm{~N} \\
r^{2}=0,99\end{array}$ \\
\hline
\end{tabular}


variaram de 5,8 a 9,3 e 13,6 a $24,5 \mathrm{mg} \mathrm{kg}^{-1}$ respectivamente (SREK et al., (2010).

De acordo com White et al. (2009), os teores dos nutrientes presentes nos tubérculos sáo influenciados por fatores ambientais e genéticos. Além destes, ReIs Júnior e Monnerat (2001) e White e Broadley (2005) relataram que estas diferenças são, provavelmente, consequência de diferentes práticas de adubação e irrigação.

Os fatores ambientais influenciam a taxa de crescimento das plantas, como é o caso de temperatura, intensidade de luz e irrigação (Harris, 1992; Nunes et al., 2006 e Timlin et al., 2006) e disponibilidade de nutrientes presentes no solo (White et al., 2009). Ainda, estes autores relataram que a aplicação de $\mathrm{N}$ pode alterar o teor de outros nutrientes presentes nos tubérculos. Diante disse, Harris (1992) e Allison et al. (2001) também relataram que a aplicaçáo de $\mathrm{N}$ acarreta pouco efeito sobre o teor de $\mathrm{K}, \mathrm{Ca}$ e $\mathrm{Mg}$, mas, por outro lado, pode haver diminuiçáo no teor de $\mathrm{P}$ e Fe nos tubérculos de batata.

A quantidade de nutrientes exportada pela planta depende de diversos fatores, como espécie, cultivar, clima, e podem ser utilizadas para calibrar a recomendação de fertilizantes (Marschner, 1995), desde que reflitam determinada interação genótipo $\mathrm{x}$ ambiente $\mathrm{x}$ manejo da adubação.
Em todas as cultivares, houve efeito de doses de $\mathrm{N}$ sobre a exportação de N, P e Mn pelos tubérculos (Tabelas 3, 4, 5 e 6) e, em pelo menos uma cultivar, houve efeito de doses de $\mathrm{N}$ sobre a exportação de $\mathrm{K}, \mathrm{Ca}, \mathrm{Mg}, \mathrm{S}$, $\mathrm{Cu}$ e Fe pelos tubérculos (Tabelas 3, 4, 5 e 6). O efeito de doses de $\mathrm{N}$ sobre a exportação de $\mathrm{P}, \mathrm{K}, \mathrm{Ca}, \mathrm{Mg}, \mathrm{S}, \mathrm{Fe}$ e $\mathrm{Zn}$ foi resultado do efeito do $\mathrm{N}$ na produção de matéria seca de tubérculos, pois o $\mathrm{N}$ não influenciou o teor destes nutrientes nos tubérculos.

As quantidades exportadas de macro e micronutrientes, associadas à dose de $\mathrm{N}$ correspondente à máxima produtividade de tubérculo comercial de tubérculos das cultivares, estão especificadas na tabela 7. O tubérculo de batata, em relação ao caule e à folha, é o órgão com maior acúmulo de nutrientes, exceção do Ca (Paula et. al., 1986b). Estes autores relataram que em torno de $98 \%$ e $88 \%$ do $\mathrm{N}$ estavam acumulados nos tubérculos na cultivar Achat, enquanto $86 \%$ e $80 \%$, respectivamente, sem e com adubação, na cultivar Mantiqueira. Paula et. al. (1986a) relatam valor de 42,60 $\mathrm{kg} \mathrm{ha}^{-1}$ de N exportados pelos tubérculos e Mustonen et al. (2010) verificaram dose de $120 \mathrm{~kg} \mathrm{ha}^{-1}$ de $\mathrm{N}$, valores médios de $105,1 \mathrm{~kg} \mathrm{ha}^{-1}$ de $\mathrm{N}$, referente a dois anos de cultivos. SREK et al. (2010) relataram que a exportação máxima de $\mathrm{K}$ e de $\mathrm{Mg}$ nos tubérculos foi, respectivamente, 157 e $8,2 \mathrm{~kg} \mathrm{ha}^{-1}$. Em estudos realizados por ReIs Júnior e

Tabela 3. Equações ajustadas para a exportação dos nutrientes na matéria seca dos tubérculos, em função de doses de nitrogênio (N), cultivar Ágata. Viçosa (MG), 2006

\begin{tabular}{|c|c|c|c|}
\hline Nutriente & Unidade & Equações ajustadas & $\mathbf{R}^{2}$ \\
\hline $\mathrm{N}$ total & kg ha-1 & $\hat{Y}=69,8520+0,211649 * N-0,000649625^{*} \mathrm{~N}^{2}$ & 0,99 \\
\hline$P$ & $\mathrm{~kg} \mathrm{ha}^{-1}$ & $\hat{Y}=14,1899+0,0125084 * \sqrt{N}-0,0658007^{*} N$ & 0,93 \\
\hline K & $\mathrm{kg} \mathrm{ha}^{-1}$ & $\hat{Y}=142,435+0,0677773^{*} \sqrt{N}-0,329564^{*} N$ & 0,93 \\
\hline $\mathrm{Ca}$ & $\mathrm{kg} \mathrm{ha}^{-1}$ & $\hat{Y}=40,92$ & - \\
\hline $\mathrm{Mg}$ & $\mathrm{kg} \mathrm{ha}^{-1}$ & $\hat{Y}=5,46$ & - \\
\hline $\mathrm{S}$ & $\mathrm{kg} \mathrm{ha}^{-1}$ & $\hat{Y}=7,74238+0,244125^{*} \sqrt{N}-0,0101768^{*} N$ & 0,96 \\
\hline $\mathrm{Cu}$ & $\mathrm{g} \mathrm{ha}^{-1}$ & $\hat{Y}=16$ & - \\
\hline $\mathrm{Mn}$ & $\mathrm{g} \mathrm{ha}^{-1}$ & $\hat{Y}=71,3848+0,298876^{*} \mathrm{~N}-0,000873395^{*} \mathrm{~N}^{2}$ & 0,93 \\
\hline $\mathrm{Fe}$ & $\mathrm{g} \mathrm{ha}^{-1}$ & $\hat{Y}=1386,39+24,3410^{*} N-0,0741287^{*} N^{2}$ & 0,71 \\
\hline $\mathrm{Zn}$ & $\mathrm{g} \mathrm{ha}^{-1}$ & $\hat{Y}=124$ & - \\
\hline
\end{tabular}

* - Significativo a $5 \%$ de probabilidade pelo teste " $\mathrm{t}$ ".

Tabela 4. Equações ajustadas para a exportação dos nutrientes na matéria seca dos tubérculos, em função de doses de nitrogênio (N), cultivar Asterix Viçosa (MG), 2006

\begin{tabular}{|c|c|c|c|}
\hline Nutriente & unidade & Equações ajustadas & $\mathbf{R}^{2}$ \\
\hline $\mathrm{N}$ total & $\mathrm{kg} \mathrm{ha}^{-1}$ & $\hat{Y}=51,3372+0,413615^{*} \mathrm{~N}-0,000911295^{*} \mathrm{~N}^{2}$ & 0,99 \\
\hline $\mathrm{P}$ & $\mathrm{kg} \mathrm{ha}^{-1}$ & $\hat{Y}=13,7873+0,0118454^{*} \mathrm{~N}$ & 0,82 \\
\hline K & $\mathrm{kg} \mathrm{ha}^{-1}$ & $\hat{Y}=111,610+0,100892 * \mathrm{~N}$ & 0,62 \\
\hline $\mathrm{Ca}$ & $\mathrm{kg} \mathrm{ha}^{-1}$ & $\hat{Y}=26,8368+0,0799106^{*} \mathrm{~N}-0,000185362^{*} \mathrm{~N}^{2}$ & 0,94 \\
\hline $\mathrm{Mg}$ & $\mathrm{kg} \mathrm{ha}^{-1}$ & $\hat{Y}=2,71789+0,0137484^{*} \mathrm{~N}-0,0000355790^{*} \mathrm{~N}^{2}$ & 0,98 \\
\hline $\mathrm{S}$ & $\mathrm{kg} \mathrm{ha}^{-1}$ & $\hat{Y}=5,45546+0,196688^{*} \sqrt{N}-0,00381336^{*} N$ & 0,99 \\
\hline $\mathrm{Cu}$ & $\mathrm{g} \mathrm{ha}^{-1}$ & $\hat{Y}=13,0372+0,0473498^{*} \mathrm{~N}$ & 0,98 \\
\hline Mn & $\mathrm{g} \mathrm{ha}^{-1}$ & $\hat{Y}=62,9627+0,148958^{*} \mathrm{~N}$ & 0,76 \\
\hline $\mathrm{Fe}$ & $\mathrm{g} \mathrm{ha}^{-1}$ & $\hat{Y}=2322$ & - \\
\hline $\mathrm{Zn}$ & $\mathrm{g} \mathrm{ha}^{-1}$ & $\hat{Y}=134$ & - \\
\hline
\end{tabular}

* - Significativo a $5 \%$ de probabilidade pelo teste " $\mathrm{t}$ ". 
Tabela 5. Equaçôes ajustadas para a exportação dos nutrientes na matéria seca dos tubérculos, em função de doses de nitrogênio (N), cultivar Atlantic. Viçosa (MG), 2006

\begin{tabular}{|c|c|c|c|}
\hline Nutriente & unidade & Equações ajustadas & $\mathbf{R}^{2}$ \\
\hline $\mathrm{N}$ total & $\mathrm{kg} \mathrm{ha}^{-1}$ & $\hat{Y}=73,4088+0,442818^{*} \mathrm{~N}-0,000919229^{*} \mathrm{~N}^{2}$ & 0,94 \\
\hline $\mathrm{P}$ & $\mathrm{kg} \mathrm{ha}^{-1}$ & $\hat{Y}=19,9911+0,0729280 * N-0,000236526 * N^{2}$ & 0,95 \\
\hline K & $\mathrm{kg} \mathrm{ha}^{-1}$ & $\hat{Y}=199,50$ & - \\
\hline $\mathrm{Ca}$ & $\mathrm{kg} \mathrm{ha}^{-1}$ & $\hat{Y}=48,7479+0,158078^{*} N-0,000422393^{*} \mathrm{~N}^{2}$ & 0,91 \\
\hline $\mathrm{Mg}$ & $\mathrm{kg} \mathrm{ha}^{-1}$ & $\hat{Y}=6,89$ & - \\
\hline $\mathrm{S}$ & $\mathrm{kg} \mathrm{ha}^{-1}$ & $\hat{Y}=10,6923+0,0420304^{*} N-0,000125093^{*} N^{2}$ & 0,89 \\
\hline $\mathrm{Cu}$ & $\mathrm{g} \mathrm{ha}^{-1}$ & $\hat{Y}=5,29175+0,0527424^{*} \mathrm{~N}$ & 0,90 \\
\hline $\mathrm{Mn}$ & $\mathrm{g} \mathrm{ha}^{-1}$ & $\hat{Y}=156,696-0,129796^{*} N$ & 0,87 \\
\hline $\mathrm{Fe}$ & $\mathrm{g} \mathrm{ha}^{-1}$ & $\hat{Y}=3481$ & - \\
\hline $\mathrm{Zn}$ & $\mathrm{g} \mathrm{ha}^{-1}$ & $\hat{Y}=134$ & - \\
\hline
\end{tabular}

* - Significativo a $5 \%$ de probabilidade pelo teste " $\mathrm{t}$ ".

Tabela 6. Equaçôes ajustadas para a exportação dos nutrientes na matéria seca dos tubérculos, em função de doses de nitrogênio (N), cultivar Monalisa Viçosa (MG), 2006

$\begin{array}{lccc}\text { Nutriente } & \text { Unidade } & \text { Equações ajustadas } & \mathbf{R}^{2} \\ \mathrm{~N} \text { total } & \mathrm{kg} \mathrm{ha}^{-1} & \hat{Y}=49,4620+0,0758855^{*} \mathrm{~N} & 0,90 \\ \mathrm{P} & \mathrm{kg} \mathrm{ha}^{-1} & \hat{Y}=10,4993+0,0100966^{*} \mathrm{~N} & 0,73 \\ \mathrm{~K} & \mathrm{~kg} \mathrm{ha}^{-1} & \hat{Y}=110,62 & - \\ \mathrm{Ca} & \mathrm{kg} \mathrm{ha}^{-1} & \hat{Y}=29,18 & - \\ \mathrm{Mg} & \mathrm{kg} \mathrm{ha}{ }^{-1} & \hat{Y}=3,38 & - \\ \mathrm{S} & \mathrm{kg} \mathrm{ha}^{-1} & \hat{Y}=5,92 & - \\ \mathrm{Cu} & \mathrm{g} \mathrm{ha}^{-1} & \hat{Y}=8,54643+0,0224932 * \mathrm{~N} & 0,99 \\ \mathrm{Mn} & \mathrm{g} \mathrm{ha}^{-1} & \hat{Y}=52,3797+0,206401 * \mathrm{~N}-0,000374053^{*} \mathrm{~N}^{2} & 0,99 \\ \mathrm{Fe} & \mathrm{g} \mathrm{ha}^{-1} & \hat{Y}=2143 & - \\ \mathrm{Zn} & \mathrm{g} \mathrm{ha}^{-1} & \hat{Y}=106 & -\end{array}$

* - Significativo a $5 \%$ de probabilidade pelo teste " $\mathrm{t}$ ".

Tabela 7. Exportação de macro e de micronutrientes associadas à dose de nitrogênio $(\mathrm{N})$ proporcionou a máxima produtividade comercial de tubérculos $(\mathrm{DON})^{1}$ das cultivares de batata Ágata, Asterix, Atlantic e Monalisa. Viçosa (MG), 2006

\begin{tabular}{lcccc} 
Exportação & \multicolumn{3}{c}{ Cultivares } \\
\cline { 2 - 5 } $\mathrm{N}$ total $\left(\mathrm{kg} \mathrm{ha}^{-1}\right)$ & Ágata & Asterix & Atlantic & Monalisa \\
$\mathrm{P}\left(\mathrm{kg} \mathrm{ha}^{-1}\right)$ & 87,07 & 98,07 & 122,80 & 64,12 \\
$\mathrm{~K}\left(\mathrm{~kg} \mathrm{ha}^{-1}\right)$ & 19,34 & 16,30 & 25,50 & 12,45 \\
$\mathrm{Ca}\left(\mathrm{kg} \mathrm{ha}^{-1}\right)$ & 8,88 & 133,02 & 199,50 & 110,62 \\
$\mathrm{Mg}\left(\mathrm{kg} \mathrm{ha}^{-1}\right)$ & 40,92 & 35,44 & 63,48 & 29,18 \\
$\mathrm{~S}\left(\mathrm{~kg} \mathrm{ha}^{-1}\right)$ & 5,46 & 4,03 & 6,89 & 3,38 \\
$\mathrm{Cu}\left(\mathrm{g} \mathrm{ha}^{-1}\right)$ & 9,19 & 7,51 & 14,21 & 5,92 \\
$\mathrm{Mn}\left(\mathrm{g} \mathrm{ha}^{-1}\right)$ & 16,0 & 23,1 & 14,5 & 12,9 \\
$\mathrm{Fe}\left(\mathrm{g} \mathrm{ha}^{-1}\right)$ & 96,9 & 94,6 & 179,5 & 64,6 \\
Zn $\left(\mathrm{g} \mathrm{ha}^{-1}\right)$ & 3383 & 2322 & 3481 & 2143 \\
\hline
\end{tabular}

(1) DON para as cultivares Ágata, Asterix, Atlantic e Monalisa foram de:168,18; 212,22; 175,45 e 193,18 $\mathrm{kg}^{-1} \mathrm{~h}^{-1}$ de N respectivamente.

Monnerat (2001), aos 48 dias após a emergência, foram contatadas nos tubérculos exportaçóes médias de $10,9 \mathrm{~kg} \mathrm{ha}^{-1}$ de $\mathrm{N}_{-} \mathrm{NO}_{3} ; 73,6 \mathrm{~kg} \mathrm{ha}^{-1}$ de N-NH$; 11,7$ $\mathrm{kg} \mathrm{ha}^{-1}$ de P; $82,3 \mathrm{~kg} \mathrm{ha}^{-1}$ de K; $1,28 \mathrm{~kg} \mathrm{ha}^{-1}$ de Ca; 5,33 $\mathrm{kg} \mathrm{ha}^{-1}$ de Mg; 6,65 $\mathrm{kg} \mathrm{ha}^{-1}$ de S; 6,20 $\mathrm{kg} \mathrm{ha}^{-1}$ de Cl, 34,4 $\mathrm{g} \mathrm{ha}^{-1}$ de Mn e 60,4 $\mathrm{g} \mathrm{ha}^{-1}$ de Zn.

A eficiência de exportação de $\mathrm{N}$, calculada pela relação entre a quantidade de $\mathrm{N}$ exportada nos tubérculos e a dose ótima de N foi 51,8; 46,2; 70,0 e 33,2\% para Ágata, Asterix, Atlantic e Monalisa respectivamente. ZeBARTH et al. (2006) relataram que a eficiência de utilização do N é normalmente menor quanto maior a dose de $\mathrm{N}$ aplicada. A eficiência de exportaçáo de $\mathrm{N}$ varia em funçáo da produçáo de matéria seca do tubérculo e do teor de $\mathrm{N}$ nesse órgão, os quais dependem de fatores gerenciais, ambientais e genotípicos envolvidos nos diversos processos que ocorrem na planta, como absorção e translocação de $\mathrm{N}$, crescimento, desenvolvimento e partiçăo de assimilados. Condiçôes favoráveis ao crescimento e à produção de tubérculos têm efeito positivo na recuperaçáo do $\mathrm{N}$ pelos tubérculos de batata e valores de 30\% a 60\% de recuperação do $\mathrm{N}$ adicionado como fertilizante, dependendo do 
ano e do modo de aplicar o fertilizante, são encontrados na literatura (Maidl et al., 2002).

Nas cultivares de batata Ágata, Asterix, Atlantic e Monalisa năo há efeito de doses de $\mathrm{N}$ sobre o teor de $\mathrm{K}$, $\mathrm{Ca}, \mathrm{Mg}, \mathrm{S}$, Fe e Zn. O teor de $\mathrm{N}$ e a exportação de $\mathrm{N}, \mathrm{P}$ e Mn pelos tubérculos, ao contrário, foram influenciadas pelas doses de $\mathrm{N}$ aplicadas em todas as cultivares, embora com padrōes diferenciados.

\section{REFERÊNCIAS}

AGRIANUAL. Anuário estatístico da agricultura brasileira. São Paulo: FNP, 2009.

ALLISON, M.F.; FOWLER, J.H.; ALLEN, E.J. Factors affecting the magnesium nutrition of potatoes (Solanum tuberosum). Journal of Agricultural Science, v.137, p.397-409, 2001.

BLANHAR, C.M.; REHM, G.; CALDWELL, A.C. Súlfurin plant material by digestion with nitric and perchloric acid. Proceedings of the Soil Science Society of America, v.29, p.71-72, 1965.

BOINK, A.; SPEIJERS, G. Healths effects of nitrates and nitrites, a review. Acta Horticulture, v.563, p.29-36, 2001.

BRAGA, J.M.; DEFELIPO, B. Determinação espectrofotométrica de fósforo em extratos de solos e plantas. Revista Ceres, v.21, p.7385, 1974.

BROADLEY, M.R.; WHITE, P.J.; BRYSON, R.J.; MEACHAM, M.C.; BOWEN, H.C.; JOHNSON, S.E.; HAWKESFORD, M.J.; MCGRATH, S.P.; ZHAO, F.-J.; BREWARD, N.; HARRIMAN, M.; TUCKER, M. Biofortification of UK food crops with selenium. Proceedings of the Nutrition Society, v.65, p.169-181, 2006.

CATALDO, D.A.; HAROON, M.; SCHRADER, L.E.; YOUNES, V.L. Rapid colorimetric determination of nitrate in plant tissue by nitration of salicylic acid. Communications in Soil Science and Plant Analysis, v.6, p.71-80, 1975.

FONTES, P.C.R.; BRAUN, H.; BUSATO, C.; CECON, P.R. Economic optimum nitrogen fertilization rates and nitrogen fertilization rate effects on tuber characteristics of potato cultivars. Potato Research, v.53, p.167-179, 2010.

GEREMEW, E.B.; STEYN, J.M.; ANNANDALE, J. G. Evaluation of growth performance and dry matter partitioning of four processing potato (Solanum tuberosum) cultivars. New Zealand Journal of Crop and Horticultural Science. v.35, p.385393, 2007.

HARRIS, P.M. Mineral Nutrition. In: Harris, P.M. (ed), The Potato Crop: The Scientific Basis for Improvement. Chapman and Hall, London, 1992. p.162-213.

HAVERKORT, A.J.; VERHAGEN, A. Climate change and its repercussions for the potato supply chain. Potato Research, v.51, p.223-237, 2008.

JACKSON, M. L. Soil chemical analysis. Englewood Cliffs, Prentice Hall, 1958. 498p.
MAIDL, F.X.; BRUNNER, H.; STICKSEL, E. Potato uptake and recovery of nitrogen ${ }^{15} \mathrm{~N}$-enriched ammonium nitrate. Geoderma, v.105, p.167-177, 2002.

MARSCHNER, H. Mineral nutrition of higher plants. 2.ed. San Diego: Academic Press, 1995. 889p.

MUSTONEN, L.; WALliUS, E.; HURME, T. Nitrogen fertilization and yield formation of potato during a short growing period. Agricultural and Food Science, v.19, p.173-183, 2010.

NUNES, J.C.S.; FONTES, P.C.R.; ARAÚJO, E.F.; SEDIYAMA, C. Potato plant growth and macronutrients uptake as affected by soil tillage and irrigation systems. Pesquisa Agropecuária Brasileira, v.41, p.1787-1792, 2006.

PAULA, M.B.; FONTES, P.C.R.; NOGUEIRA, F.D. Absorção de micronutrientes por cultivares de batata em presença ou ausência de adubação. Horticultura Brasileira, v.4, p.3-8, 1986 a.

PAULA, M.B.; FONTES, P.C.R.; NOGUEIRA, F.D. Produção de matéria seca e absorçấo de macronutrientes por cultivares de batata. Horticultura Brasileira, v.4, p.10-16, 1986b.

REIS JÚNIOR, R.A.; MONNERAT, P.H. Exportação de nutrientes nos tubérculos de batata em funçáo de doses de sulfato de potássio. Horticultura Brasileira, v.19, p.227-231, 2001.

SHARIFI, M.; ZEBARTH, B.J.; HAJABBASI, M.A.; KALBASI, $M$. Dry matter and nitrogen accumulation and root morphological characteristics of two clonal selections of 'Russet Norkotah' potato as affected by nitrogen fertilization. Journal of Plant Nutrition, v.28, p.2243-2253, 2005.

SILVA, M.C.C.; FONTES, P.C.R.; MIRANDA, G.V. Índice SPAD e produção de batata, em duas épocas de plantio, em função de doses de nitrogênio. Horticultura Brasileira, v.27, p.17-22, 2009 .

SREK, P.; HEJCMAN, M.; KUNZOVÁ, E. Multivariate analysis of relationship between potato (Solanum tuberosum L.) yield, amount of applied elements, their concentrations in tubers and uptake in a long-term fertilizer experiment. Field Crops Research, v.118, p.183-193, 2010.

TIMLIN, D.; RAHMAN, S.M.L.; BAKER, J.; REDDY, V.R.; FLEISHER, D.; QUEBEDEAUX, B. Whole plant photosynthesis, development, and carbon partitioning in potato as a function of temperature. Agronomy Journal, v.98, p.1195-1203,2006.

WALWORTH, J.L.; MUNIZ, J.E. A compendium of tissue nutrient concentrations for field-grown potatoes. American Potato Journal, v.70, p. 578-596, 1993.

WHITE, P.J.; BROADLEY, M.R. Historical variation in the mineral composition of edible horticultural products. Journal of Horticultural Science and Biotechnology, v.80, p.660-667, 2005.

WHITE, P.J.; BRADSHAW, J.E.; DALE, M.F.B.; RAMSAY, G.; HAMMOND, J.P. e BROADLEY, M.R. Relationships between yield and mineral concentrations in potato tubers. HortScience, v.44, p.6-11, 2009. 
ZEBARTH, B.J.; LECLERC, Y.; MOREAU, G..; BOTHA, E. Rate and timing nitrogen fertilization of Russet Burbank potato: yield and processing quality. Canadian Journal of Plant Science, v. 84, p.855-863, 2004.

ZEBARTH, B.J.; ARSENAULT, W.J.; SANDERSON, J.B. Effect of seedpiece spacing and nitrogen fertilization on tuber yield, yield components and nitrogen use efficiency parameters of two potato cultivars. American Journal of Potato Research, v.83, p.289-296, 2006.
ZEBARTH, B.J.; ROSEN, C. J. Research perspective on nitrogen BMP development for potato. American Journal of Potato Research, v.84, p.3-18, 2007.

ZEBARTH, B.J.; TARN, T. R.; JONG, H.; MURPHY, A. Nitrogen use efficiency characteristics of andígena and diploid potato selections. American Journal of Potato Research, v.85, p.210-218, 2008. 